\title{
Thermal body patterns for healthy Brazilian adults (male and female)
}

\author{
João Carlos Bouzas Marins ${ }^{a, *}$, Alex Andrade Fernandes ${ }^{a}$, Sergio Piñonosa Cano ${ }^{b}$, \\ Danilo Gomes Moreira a, Fabrício Souza da Silva ${ }^{a}$, Carlos Magno Amaral Costa a , \\ Ismael Fernandez-Cuevas $^{\mathrm{b}}$, Manuel Sillero-Quintana ${ }^{\mathrm{b}}$
}

${ }^{a}$ Human Performance Laboratory - LAPEH, Universidade Federal de Viçosa, Viçosa, Brazil

${ }^{\mathrm{b}}$ Faculty of Physical Activity and Sport Sciences - INEF, Universidad Politécnica de Madrid, Madrid, Spain

\section{A R T I C L E I N F O}

\section{Article history:}

Received 15 June 2013

Received in revised form

27 February 2014

Accepted 27 February 2014

Available online 7 March 2014

\section{Keywords:}

Infrared thermography

Brazilian profile

Skin temperature

Thermal symmetry

\begin{abstract}
A B S T R A C T
The aim of this study was to establish the skin temperature $\left(T_{\text {sk }}\right)$ thermal profile for the Brazilian population and to compare the differences between female and male Brazilian adults. A total of 117 female and 103 male were examined with a thermographic camera. The $T_{\mathrm{sk}}$ of 24 body regions of interest (ROI) were recorded and analyzed. Male $T_{\mathrm{sk}}$ results were compared to female and $10 \mathrm{ROI}$ were evaluated with respect to the opposite side of the body (right vs. left) to identify the existence of significant contralateral $T_{\mathrm{sk}}$ differences $\left(\Delta T_{\mathrm{sk}}\right)$. When compared right to left, the largest contralateral $\Delta T_{\text {sk }}$ was $0.3^{\circ} \mathrm{C}$. The female vs. male analysis yielded significant differences $(p<0.05)$ in 13 of the 24 ROI. Thigh regions, both ventral and dorsal, had the highest $\Delta T_{\text {sk }}$ by sex $\left(\approx 1.0^{\circ} \mathrm{C}\right) . T_{\text {sk }}$ percentile below $P_{5}$ or $P_{10}$ and over $P_{90}$ or $P_{95}$ may be used to characterize hypothermia and hyperthermia states, respectively. Thermal patterns and $T_{\text {sk }}$ tables were established for Brazilian adult men and women for each ROI. There is a low $T_{\mathrm{sk}}$ variation between sides of the body and gender differences were only significant for some ROIs.
\end{abstract}

(c) 2014 Elsevier Ltd. All rights reserved.

\section{Introduction}

Infrared Thermography (IRT) is a technique that allows visualization of the heat radiated from a body using infrared emission, a spectrum that is not visible to humans (Hildebrandt et al., 2010; Pascoe et al., 2008). This technology is used in the medical field, where it can provide doctors with information about the physiological responses associated with skin temperatures $\left(T_{\mathrm{sk}}\right)$ to identify different types of pain syndromes (Al-Nakhli et al., 2012), changes in the $T_{\text {sk }}$ (Park et al., 2012, Howell et al., 2009, George et al., 2008), vascular deficiencies (Huang et al., 2011; Brisoschi et al., 2003), or neurological problems (Zaproudina et al., 2006); provide assistance in cardiac interventions (Brisoschi et al., 2003); or help in cancer diagnosis and monitoring (Arora et al., 2008). Recently, thermography has also been proposed as a way to prevent sports injuries (Sillero-Quantana et al., 2011; GómezCarmona et al., 2011), control training load (Akimov et al., 2010), or study thermal responses during and after exercise (Hildebrandt et al., 2010; Merla et al., 2010; Marins et al., 2012a, 2012b; Merla and Romani 2008; Garagiola and Giani, 1990). Most thermography studies evaluate contralateral $T_{\mathrm{sk}}$ differences $\left(\Delta T_{\mathrm{sk}}\right)$ existing in pathological conditions such as cancer (Acharya et al., 2012; Arora

\footnotetext{
* Correspondence to: Universidade Federal de Viçosa, Departamento de Educação Física, Laboratório de Performance Humana, Viçosa-Minas, Gerais, CEP 36570-000, Brazil. Tel.: +55 31 38992249; fax: + 553138992061.

E-mail address: jcbouzas@ufv.br (J.C.B. Marins).
}

et al., 2008) or spinal disorders (Ammer, 2010). In those cases, contralateral $\Delta T_{\mathrm{sk}}$ is usually the main focus. A good thermal state of the body structure is based on thermal symmetry between symmetrical parts of the body always between a temperature range. Higher contralateral differences in $T_{\mathrm{sk}}$ could mean an imbalance or impairment between symmetrical parts of the body.

There are clear indications that thermography is a valid (Ammer and Ring, 2008; Zaproudina et al., 2006) technology, which is both non-invasive and low-cost, that rapidly produces a non-contact recording of the energy irradiated from the body (Han et al., 2010; George et al., 2008; Jiang et al., 2005). It has been recently shown that a high resolution thermal image can provide interesting information about the complex thermoregulation system of the body (Pascoe et al., 2008). The development of fast and easy IRT monitoring tools allows us to obtain a general or local thermal profile of humans, including their main body regions of interest (ROI).

For an appropriate interpretation of an individual thermographic profile, it is necessary to establish a reference thermal pattern for each population group (for example, by age group, by race or for a particular disease). Although these types of studies are uncommon, some studies in adult populations with different ethnic characteristics such as Chinese (Zhu and Xin, 1999), Finish (Zaproudina et al., 2008), Portuguese (Vardasca, 2011), Taiwanese (Niu et al., 2001), or Mexican children (Kolosovas-Machuca and González, 2011) have attempted to establish population thermal patterns. Having a thermal reference allows us to evaluate normal $T_{\mathrm{sk}}$ in different body segments and the proportion of bilaterally 
(side-to-side). According to Niu et al. (2001) and Uematsu (1985), a $\Delta T_{\text {sk }}$ greater than $0.5^{\circ} \mathrm{C}$ between two body segments strongly indicates a functional disorder in the assessed ROI.

Thermographic records also show the complex physiological response to strength training involving the skeletal muscle (metabolism), the cardiovascular system (blood flow), the nervous system (central and local) and the adrenergic system (Johnson and Kellogg, 2010; Cheuvront et al., 2010). The regulation of body temperature to maintain internal temperature at adequate levels is complex. The hypothalamus and multiple sensors and effectors act together, providing feedback to control the system (Werner, 2010) and consequently affect the $T_{\text {sk }}$.

To adequately interpret thermographic data, a set of internal factors such as age (Falk and Dotan, 2011; Charkoudian, 2010; Niu et al., 2001), gender (Falk and Dotan, 2011), level of fitness (Magalhães et al., 2010; Merla et al., 2005), and external factors including the degree of hydration (Charkoudian, 2010), clothing (Gonzales et al., 2011) or environmental conditions (Morris et al., 2005) should be considered. Furthermore, an appropriate protocol for infrared imaging is crucial to obtain quality thermographic images (Ammer and Ring, 2008). Our study has followed their guidelines considering the dark background, the distance from the camera, the position of the camera, the range of temperature and the resolution.

Data for $T_{\mathrm{sk}}$ can help to establish standards of normality in different parts of the body. Establishing the standard thermal patterns in different population groups may help to identify hyperthermic or hypothermic areas, to detect contralateral $\Delta T_{\text {sk }}$ as signs of functional problems or diseases and to determine the relationships between central and peripheral temperatures, thus reducing the subjectivity in the evaluation. Establishing the values for normal resting conditions may also contribute to understanding the thermal changes of the skin during and after any physical activity.

Local thermal information is relevant not only for practitioners but also for sports physiotherapists, dieticians and coaches who advise and provide training and therapy to normal people or athletes.

Given that age factor (Kolosovas-Machuca and González, 2011; Niu et al., 2001) is crucial in thermal responses, specific data by gender for well-defined age groups such as children, adolescents, adults and elderly people are required. Therefore, the aims of this study were (a) to establish the $T_{\mathrm{sk}}$ data for Brazilian adults and (b) to compare $\Delta T_{\mathrm{sk}}$ between males and females.

\section{Material and methods}

\subsection{Participants}

A sample of two hundred and twenty young adults participated in the study, 103 men [age: $21.3 \pm 2.19$ years, height: $1.78 \pm 0.7 \mathrm{~m}$, body mass: $72.5 \pm 7.8 \mathrm{~kg}$, and Body Mass Index (BMI): $23.0 \pm$ $2.3 \mathrm{~kg} / \mathrm{m}^{2}$ ] and 117 women [age: $21.9 \pm 2.2$ years, height: $1.64 \pm 0.05 \mathrm{~m}$, body mass: $59.8 \pm 7.1 \mathrm{~kg}$, and BMI: $22.2 \pm 2.4 \mathrm{~kg} /$ $\mathrm{m}^{2}$ ]. They did not report any pain or problems in their daily activities and did not consume any medication in the 2 weeks prior to the measurements. Exclusion criteria were smoking or any pathological condition that could alter the $T_{\mathrm{sk}}$. All individuals signed a consent inform and the ethics committee of the Viçosa Federal University, Brazil approved the study procedures.

\subsection{Procedures}

Before the assessment, subjects were instructed to avoid consuming alcohol or caffeine, using any type of moisturizer or cream and performing vigorous physical exercise in the $24 \mathrm{~h}$ preceding the measurements. These recommendations were given on the day of enrollment and were assessed via questionnaire immediately before the early morning data collection.

The $T_{\mathrm{sk}}$ of the body ROI were obtained from thermographic images following the criteria described by Ring and Ammer (2012, 2008). Evaluations were performed at the Human Performance Laboratory (LAPEH) of the Federal University of Viçosa from October 2010 to March 2011 (spring and summer season in Brazil). Subjects were instructed to change clothes, using a swimsuit or shorts (men) or a top and shorts (women). Soon after, they were directed to a conditioned room (Temperature: $21{ }^{\circ} \mathrm{C} \pm 0.3{ }^{\circ} \mathrm{C}$ and humidity: $67.8 \pm 3.8 \%$ ) where, after $15 \mathrm{~min}$ of adaptation to the room conditions, four thermograms for each subject were recorded including two images each (lower limbs and trunk/upper limb) of the anterior and posterior sides of the body.

Just after entering the data collection room, the subject was instructed to stand on top of a rubber mat that was $4 \mathrm{~m}$ away from the infrared imager and $0.4 \mathrm{~m}$ from the wall. The wall was covered with a black background to avoid any kind of reflection. Subjects were asked to refrain from making any type of movement, sitting, crossing their arms or legs, or scratching throughout the procedure.

The $T_{\mathrm{sk}}$ analysis included the left and right sides of the hand, forearm, upper arm, thigh and leg. In addition, $T_{\mathrm{sk}}$ data of the chest, abdomen, lower back and upper back were also collected. The $T_{\mathrm{sk}}$ averages from 24 ROI were collected by the software Smartview $^{\circledR} \quad$ Fluke $^{\circledR}$, Everett, USA). The ROI were rectangles determined by anatomical landmarks, namely (a) hand: the junction of the 3rd metacarpal with the 3rd proximal phalanx and the ulnar styloid process, (b) forearm: the distal forearm and cubital fossa (c) arm: cubital fossa and axillary line, (d) abdomen (and low back): xiphoid process and $5 \mathrm{~cm}$ below the umbilicus; (e) chest (upper back): nipple line and top edge of the sternum; (f) thigh: $5 \mathrm{~cm}$ above the superior border of the patella and the inguinal line; $(\mathrm{g})$ leg: $5 \mathrm{~cm}$ below the inferior border of the patella and $10 \mathrm{~cm}$ above the malleolus. The points corresponding to the posterior region of the body were marked using a tape measure parallel to the ground. Fig. 1 shows an example of images taken of the evaluated ROI.

The thermographic imager was a TIR-25 camera (Fluke ${ }^{\circledR}$, Everett, USA) with a measurement range of -20 to $+350{ }^{\circ} \mathrm{C}$, an accuracy of $\pm 2{ }^{\circ} \mathrm{C}$ or $2 \%$ of the measurement, a sensitivity below $0.1{ }^{\circ} \mathrm{C}$, an infrared spectral band from $7.5 \mu \mathrm{m}$ to $14 \mu \mathrm{m}$, a refresh rate of $9 \mathrm{~Hz}$ and a resolution of $160 \times 120$ pixels FPA (Focal Plane Array). Images were obtained assuming a skin emissivity of 0.98 (Ring and Ammer, 2012) and analyzed using the Smartview ${ }^{\circledR}$ software, version 3.1 .

After thermographic data collection, the subjects were weighed with an ID-M scale (Filizola ${ }^{\mathbb{R}}$, São Paulo, Brazil), and their heights were measured with a standard wall-stadiometer (Sanny ${ }^{\mathbb{R}}$, São Bernardo do Campo, Brazil).

\subsection{Statistical analysis}

We applied descriptive statistics including the means and standard deviations for data presentation. General and by gender absolute regional contralateral $\Delta T_{\text {sk }}$ were calculated for each of the 10 ROI pairs by subtracting the mean $T_{\mathrm{sk}}$ of the left side from the mean $T_{\text {sk }}$ of the right side.

After confirming the normal distribution of the variables using a Shapiro-Wilk test, significant differences between the 10 contralateral $\Delta T_{\mathrm{sk}}$ values were calculated by a paired samples Student's t-test, and the differences between the $T_{\mathrm{sk}}$ of the 20 gender-common ROI by an independent samples Student's t-test. A significance level of $\alpha=0.05$ was set for the statistic tests in the software SigmaPlot 11.0 (Systat, Chicago, USA). 

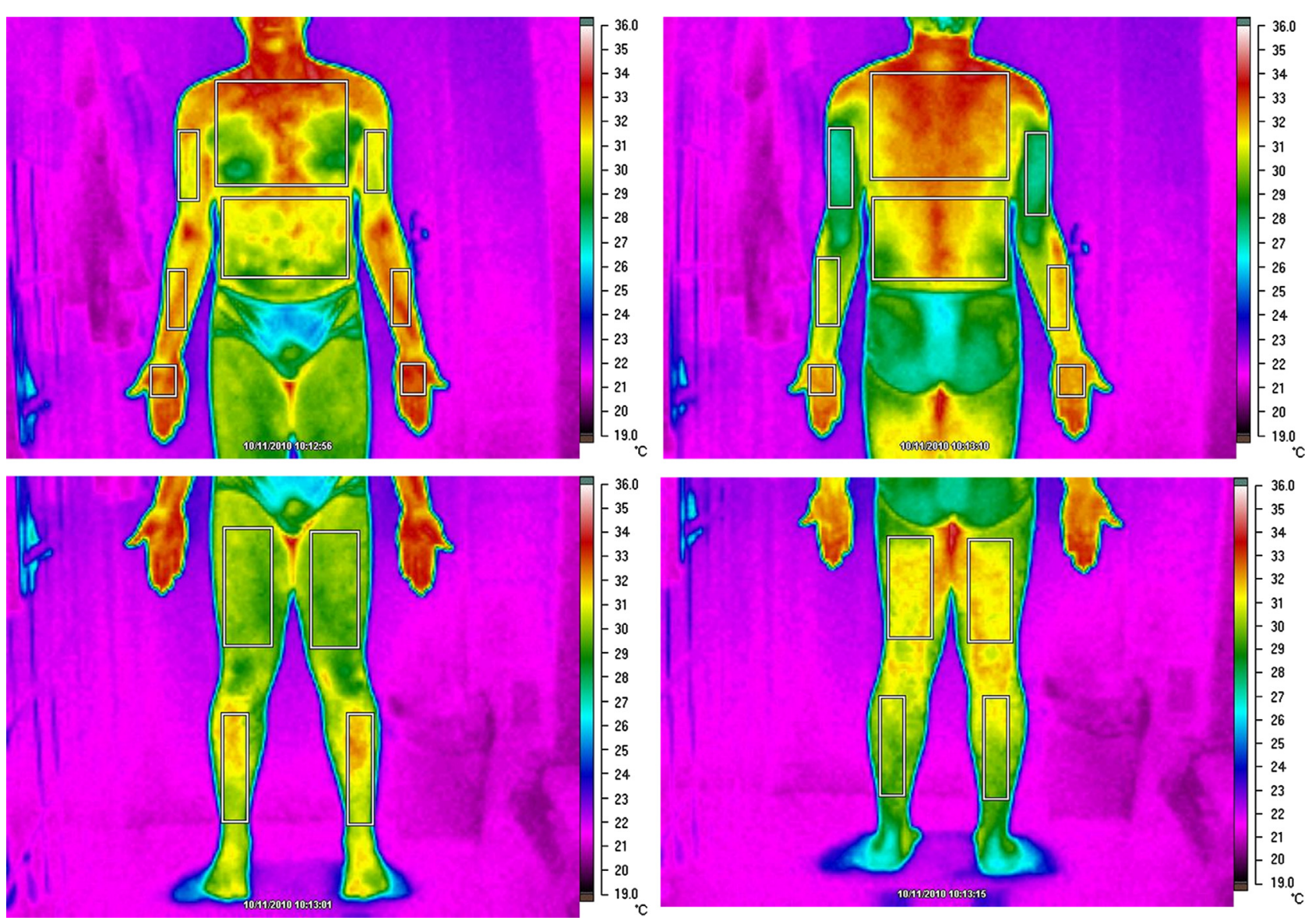

Fig. 1. Front and back infrared thermograms of a male subject and the location of the 24 measured ROI.

We also calculated the $\Delta T_{\text {sk }}$ percentage distribution in seven ranges of temperatures $\left(<0.25{ }^{\circ} \mathrm{C} ; 0.26-0.50{ }^{\circ} \mathrm{C} ; 0.51-0.70{ }^{\circ} \mathrm{C}\right.$; $0.71-1.00{ }^{\circ} \mathrm{C} ; 1.01-1.25^{\circ} \mathrm{C} ; 1.26-1.50{ }^{\circ} \mathrm{C}$ and $>1.51{ }^{\circ} \mathrm{C}$ ) for the 10 contralateral paired ROI. Finally, the percentiles $P_{5}, P_{10}, P_{50}, P_{90}$ and $P_{95}$ were obtained to establish $T_{\text {sk }}$ values for the 24 ROI.

\section{Results}

Table 1 shows the averages and standard deviations for the 24 ROI of the 220 Brazilian adults by gender as well as the mean $\Delta T_{\text {sk }}$ between the 10 paired ROI. The hand region is the area of lowest $T_{\mathrm{sk}}$ in both men and women. The hottest regions were the chest (anterior view) and upper back (posterior view) in men, while in women they were the abdomen (anterior view) and lower back (posterior view). In most of the ventral areas, males and females showed higher $T_{\mathrm{sk}}$ averages in the left side, whereas in the dorsal areas showed higher $T_{\mathrm{sk}}$ averages in the right side.

Below are the percentage distributions of $\Delta T_{\mathrm{sk}}$ for the 10 paired ROI analyzed in men (Fig. 2) and women (Fig. 3) separated into seven temperature ranges. In the Figs. 2 and 3, the hands of both men and women (13.6\% in men and $14.5 \%$ in women) in the anterior view and the forearm in the posterior view for both men and women (9.7\% and $10.3 \%$, respectively) were the regions that registered the highest percentage of cases with $\Delta T_{\text {sk }}$ greater than $1.0^{\circ} \mathrm{C}$; moreover, the anterior and posterior thigh and leg were the ROI in men and women with the lowest incidence of abnormal asymmetries, always below $2 \%$ of cases. The ranges of $\Delta T_{\mathrm{sk}}$ in the normal limits for young adults were between 53 and $89 \%$ of males and between $59 \%$ and $81 \%$ of females in the anterior view and between 63 and $92 \%$ of males and between $57 \%$ and $85 \%$ of females in the posterior view, depending on the considered ROI.

\section{Discussion}

A thermal image can be interpreted in two ways: qualitatively and quantitatively. For a qualitative analysis, the evaluator requires experience to identify abnormal hotspots and cold areas. A quantitative analysis, however, can objectively determine the existence of any thermal imbalance with more accuracy. data for $T_{\mathrm{sk}}$ on each ROI are crucial for a proper analysis of the thermogram, allowing a clearer evaluation of the subject not only in a clinical setting but also for physical therapy or even professional sports.

Quantitative analysis can be performed in two ways: first, by considering the bilateral ROI when comparing contralateral $\Delta T_{\mathrm{sk}}$ (Zaproudina et al.,2008; Uematsu et al., 1988; Zhu and Xin, 1999; Niu et al., 2001; Vardasca, 2010; Kolosovas-Machuca and González, 2011; Ben-Eliyahu, 1992) and second, by establishing the percentile values for each ROI, which has a specific thermal profile (Cabrera et al., 2008; Zaprudina et al., 2008; Niu et al., 2001).

These analyses may help interpret the data obtained for a subject. A good thermal report should identify thermal imbalances for each ROI compared with its contralateral side, and additionally, whether the patient is experiencing hyperthermia or hypothermia of each ROI. Although the thermographic results are not conclusive enough to make a definitive diagnosis, they provide the professional with some clues for carrying out further diagnostic tests to establish the causes of this abnormal $T_{\mathrm{sk}}$ behavior. 
Table 1

Mean $T_{\mathrm{sk}}\left({ }^{\circ} \mathrm{C}\right)$ and standard deviations of the 24 measured ROI, considering contralateral and gender differences ( $\left.\Delta T_{\mathrm{sk}}\right)$.

\begin{tabular}{|c|c|c|c|c|c|c|}
\hline \multirow[t]{2}{*}{ ROI } & & \multicolumn{2}{|l|}{ Male $(n=103)$} & \multicolumn{2}{|c|}{ Female $(N=117)$} & \multirow{2}{*}{$\begin{array}{l}\text { (Male vs. female) } \\
\text { Mean } \Delta T_{\mathrm{sk}} ; P\end{array}$} \\
\hline & & Average \pm SD & Mean $\Delta T_{\text {sk }}(\mathrm{R}$ vs. L); $p$ & Average \pm SD & Mean $\Delta T_{\text {sk }}($ R vs. L); $P$ & \\
\hline \multirow[t]{2}{*}{ Ventral hand } & $\mathrm{R}$ & $28.17 \pm 2.61$ & \multirow{2}{*}{$-0.17 ; p=0.00$} & $28.40 \pm 2.2$ & \multirow{2}{*}{$-0.20 ; p<0.00$} & $0.23 ; p=0.48$ \\
\hline & $\mathrm{L}$ & $28.34 \pm 2.62$ & & $28.60 \pm 2.2$ & & $0.26 ; p=0.42$ \\
\hline \multirow[t]{2}{*}{ Ventral forearm } & $\mathrm{R}$ & $30.75 \pm 1.2$ & \multirow[t]{2}{*}{$-0.21 ; p=0.00$} & $30.39 \pm 1.2$ & \multirow[t]{2}{*}{$-0.20 ; p<0.00$} & $0.36 ; p=0.03$ \\
\hline & $\mathrm{L}$ & $30.96 \pm 1.1$ & & $30.59 \pm 1.2$ & & $0.37 ; p=0.03$ \\
\hline \multirow[t]{2}{*}{ Ventral arm } & $\mathrm{R}$ & $31.25 \pm 1.3$ & \multirow[t]{2}{*}{$-0.07 ; p=0.13$} & $30.75 \pm 1.2$ & \multirow[t]{2}{*}{$-0.33 ; p<0.00$} & $0.40 ; p=0.00$ \\
\hline & $\mathrm{L}$ & $31.32 \pm 1.4$ & & $31.08 \pm 1.3$ & & $0.24 ; p=0.19$ \\
\hline \multirow[t]{2}{*}{ Ventral thigh } & $\mathrm{R}$ & $29.70 \pm 1.1$ & \multirow{2}{*}{$-0.05 ; p=0.11$} & $28.62 \pm 1.3$ & \multirow{2}{*}{$-0.10 ; p<0.00$} & $1.08 ; p<0.00$ \\
\hline & $\mathrm{L}$ & $29.75 \pm 1.2$ & & $28.72 \pm 1.3$ & & $1.03 ; p<0.00$ \\
\hline \multirow[t]{2}{*}{ Ventral leg } & $\mathrm{R}$ & $30.21 \pm 1.4$ & \multirow[t]{2}{*}{$0.02 ; p=0.51$} & $30.18 \pm 1.2$ & \multirow[t]{2}{*}{$0.07 ; p=0.04$} & $0.03 ; p=0.86$ \\
\hline & $\mathrm{L}$ & $30.19 \pm 1.4$ & & $30.11 \pm 1.2$ & & $0.08 ; p=0.65$ \\
\hline Chest & & $31.80 \pm 1.0$ & - & - & - & - \\
\hline Abdomen & & $31.56 \pm 1.1$ & - & $31.39 \pm 1.4$ & - & $0.17 ; p=0.33$ \\
\hline \multirow[t]{2}{*}{ Dorsal hand } & $\mathrm{R}$ & $28.06 \pm 2.1$ & \multirow[t]{2}{*}{$0.06 ; p=0.27$} & $28.37 \pm 1.8$ & \multirow[t]{2}{*}{$0.15 ; p=0.00$} & $0.31 ; p=0.25$ \\
\hline & $\mathrm{L}$ & $28.00 \pm 2.1$ & & $28.22 \pm 1.8$ & & $0.22 ; p=0.40$ \\
\hline \multirow[t]{2}{*}{ Dorsal Forearm } & $\mathrm{R}$ & $30.61 \pm 1.1$ & \multirow[t]{2}{*}{$0.31 ; p<0.00$} & $30.20 \pm 1.2$ & \multirow[t]{2}{*}{$0.25 ; p<0.00$} & $0.41 ; p=0.01$ \\
\hline & $\mathrm{L}$ & $30.30 \pm 1.1$ & & $29.95 \pm 1.1$ & & $0.35 ; p=0.02$ \\
\hline \multirow{2}{*}{ Dorsal arm } & $\mathrm{R}$ & $29.36 \pm 1.2$ & \multirow{2}{*}{$0.14 ; p=0.00$} & $28.59 \pm 1.4$ & \multirow{2}{*}{$0.11 ; p<0.01$} & $0.77 ; p<0.00$ \\
\hline & $\mathrm{L}$ & $29.22 \pm 1.2$ & & $28.48 \pm 1.4$ & & $0.74 ; p<0.00$ \\
\hline \multirow[t]{2}{*}{ Posterior thigh } & $\mathrm{R}$ & $30.28 \pm 1.1$ & \multirow[t]{2}{*}{$0.08 ; p=0.01$} & $29.26 \pm 1.1$ & \multirow[t]{2}{*}{$0.11 ; p=0.45$} & $1.02 ; p<0.00$ \\
\hline & $\mathrm{L}$ & $30.20 \pm 1.2$ & & $29.15 \pm 1.1$ & & $1.05 ; p<0.00$ \\
\hline \multirow[t]{2}{*}{ Calf } & $\mathrm{R}$ & $29.97 \pm 1.3$ & \multirow[t]{2}{*}{$0.09 ; p=0.00$} & $29.16 \pm 1.0$ & $0.15 ; p<0.00$ & $0.81 ; p<0.00$ \\
\hline & $\mathrm{L}$ & $29.88 \pm 1.3$ & & $29.01 \pm 1.1$ & & $0.87 ; p<0.00$ \\
\hline Upper back & - & $32.14 \pm 0.9$ & - & - & - & \\
\hline Low back & - & $31.56 \pm 1.0$ & - & $31.30 \pm 1.4$ & - & $0.26 ; p=0.12$ \\
\hline
\end{tabular}

Note: $\mathrm{R}=$ Right; $\mathrm{L}=$ Left

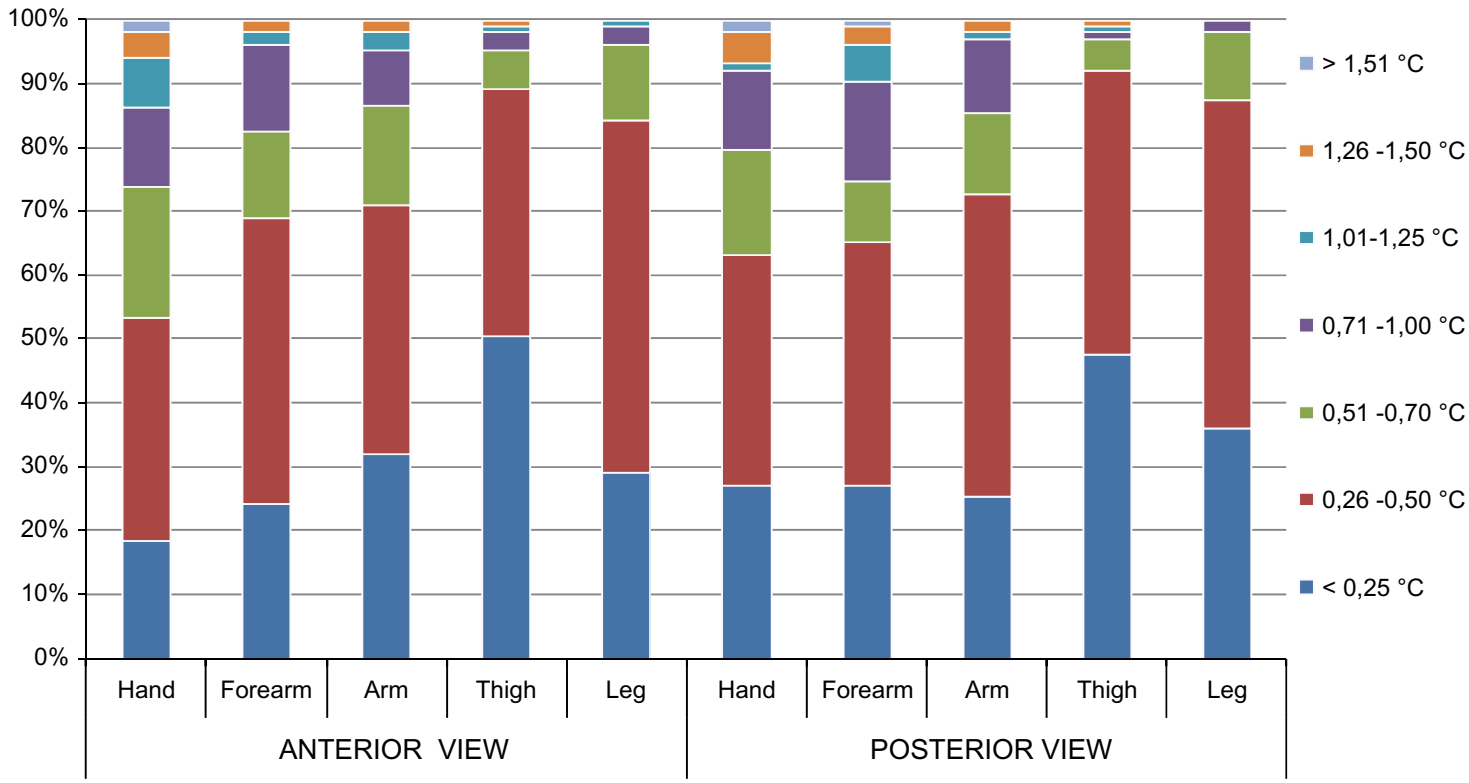

Fig. 2. Percentage distribution of $\Delta T_{\text {sk }}$ for selected paired ROI in men ( $\left.n=103\right)$.

\subsection{Contralateral analysis}

Thermal bilateral symmetry is justified by the concept of proportionality between contralateral body areas (Brisoschi et al., 2003). Our average $T_{\text {sk }}$ results are consistent with other works in the literature identifying standard right vs. left thermal differences in healthy populations (Zaproudina et al., 2008; Uematsu et al.,1988;; Zhu and Xin, 1999; Niu et al., 2001; Vardasca, 2010; Kolosovas-Machuca and González, 2011). Table 2 compares our contralateral $\Delta T_{\mathrm{sk}}$ with those reported by some authors who have analyzed the same ROI.

The results in the table above show that our absolute side-to-side $\Delta T_{\text {sk }}$ never exceeded $0.4{ }^{\circ} \mathrm{C}$, confirming the previously measured value of $0.5^{\circ} \mathrm{C}$ as the maximum normal value for contralateral ROI (Niu et al., 2001; Uematsu, 1985).

Quantitative analysis using IRT is a fast, non-invasive and safe tool (Hildebrandt et al., 2010) for general clinical analysis. When IRT results show a contralateral thermal imbalance, they can indicate disturbances in the autonomic nervous system (Herry and Frize, 2004) and peripheral blood flow (Hildebrandt et al., 2010) as well as pain syndromes (Al-Nakhli et al., 2012; Zaproudina et al., 2006). A good example of the applicability of IRT was shown previously when up to $85.7 \%$ of physiological syndromes had diagnosis confirmed through $T_{\text {sk }}$ asymmetries in contralateral evaluations (Zhu and Xin, 1999). At the moment, IRT can detect some physiological disturbances, but more elaborate 


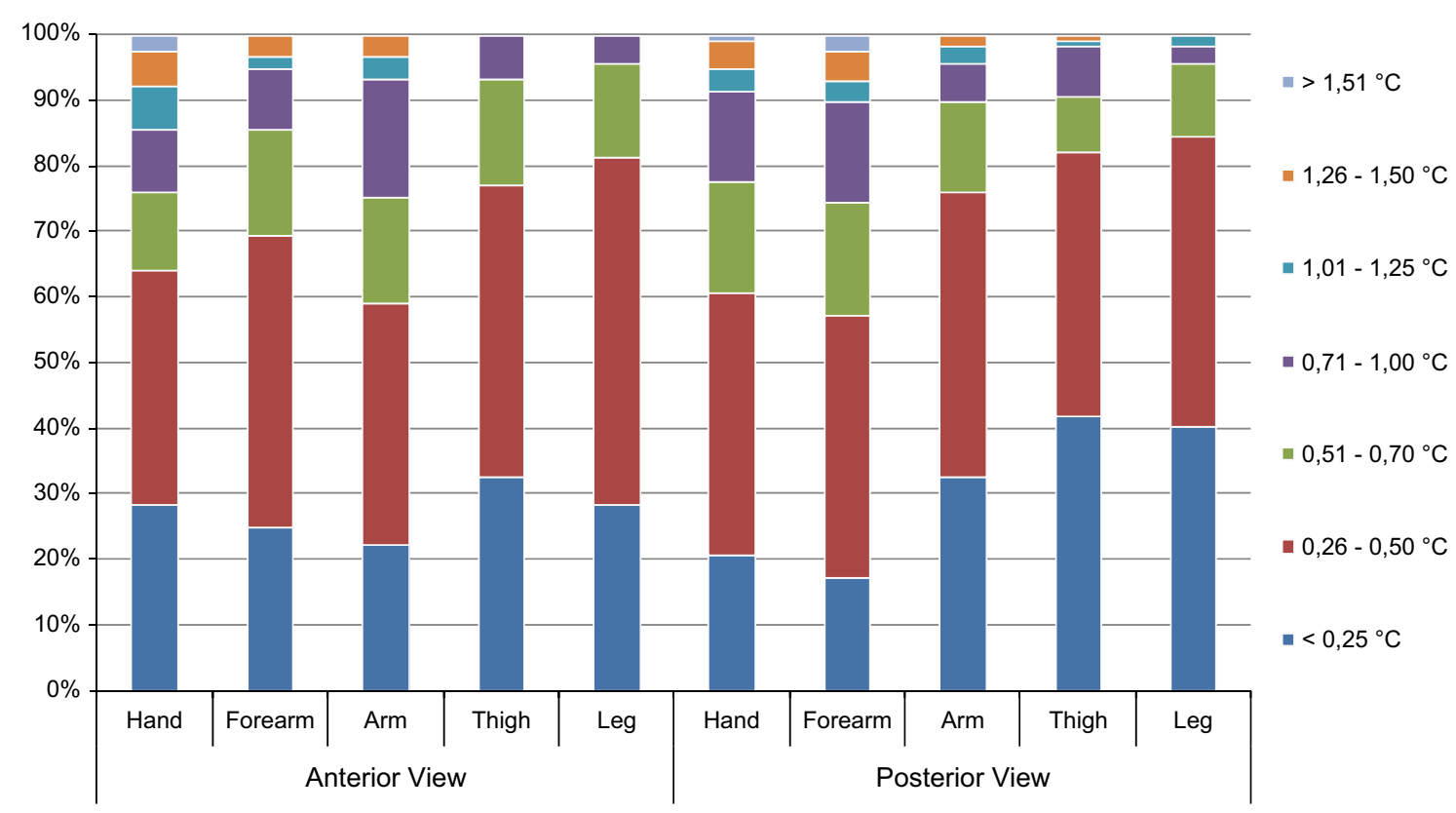

Fig. 3. Percentage distribution of $\Delta T_{\mathrm{sk}}$ for selected paired ROI in women ( $\left.n=117\right)$.

Table 2

Mean contralateral $\Delta T_{\text {sk }}$ in different studies with healthy people.

\begin{tabular}{|c|c|c|c|c|c|c|c|}
\hline \multirow{2}{*}{$\begin{array}{l}\text { Gender } \\
\text { ROI }\end{array}$} & \multicolumn{2}{|l|}{ Males } & \multirow{2}{*}{$\begin{array}{l}\text { Females } \\
\text { Our study } \\
\left(\begin{array}{l}n=117) \\
\text { Brazilian }\end{array}\right.\end{array}$} & \multicolumn{4}{|l|}{ Males and females } \\
\hline & $\begin{array}{l}\text { Our study } \\
(n=103) \\
\text { Brazilian }\end{array}$ & $\begin{array}{l}\text { Zaproudina et al. (2008) } \\
(n=16) \\
\text { Finish }\end{array}$ & & $\begin{array}{l}\text { Niu et al. (2001) } \\
(n=37) \\
\text { Taiwanese }\end{array}$ & $\begin{array}{l}\text { Uematsu et al. } \\
(1988) \\
(n=90)\end{array}$ & $\begin{array}{l}\text { Kolosovas-Machuca and González } \\
(2011)(n=25) \\
\text { Mexican children }\end{array}$ & $\begin{array}{l}\text { Zhu and Xin (1999) } \\
(n=223) \\
\text { Chinese }\end{array}$ \\
\hline $\begin{array}{r}\text { Ventral } \\
\text { Hand }\end{array}$ & 0.17 & 0.22 & 0.20 & 0.24 & 0.3 & 0.1 & 0.3 \\
\hline $\begin{array}{l}\text { Ventral } \\
\text { Forearm }\end{array}$ & 0.21 & 0.19 & 0.20 & 0.25 & 0.21 & 0.1 & 0.21 \\
\hline $\begin{array}{c}\text { Ventral } \\
\text { Arm }\end{array}$ & 0.07 & 0.21 & 0.33 & 0.27 & 1.19 & 0.1 & 1.19 \\
\hline $\begin{array}{r}\text { Ventral } \\
\text { Thigh }\end{array}$ & 0.05 & 0.15 & 0.10 & 0.24 & 0.18 & 0 & 0.18 \\
\hline Ventral Leg & 0.02 & 0.17 & 0.07 & 0.27 & ND & ND & ND \\
\hline $\begin{array}{l}\text { Dorsal } \\
\text { Hand }\end{array}$ & 0.06 & 0.22 & 0.15 & 0.31 & 0.36 & 0.1 & 0.36 \\
\hline $\begin{array}{l}\text { Dorsal } \\
\text { Forearm }\end{array}$ & 0.31 & 0.19 & 0.25 & 0.31 & 0.26 & 0.1 & 0.26 \\
\hline Dorsal Arm & 0.14 & 0.24 & 0,11 & 0.39 & 0.37 & 0.1 & 0.37 \\
\hline $\begin{array}{c}\text { Dorsal } \\
\text { Thigh }\end{array}$ & 0.08 & 0.14 & 0.11 & 0.23 & 0.25 & 0 & 0.25 \\
\hline Dorsal Calf & 0.09 & 0.21 & 0.15 & 0.29 & 0.18 & ND & 0.18 \\
\hline
\end{tabular}

${ }^{*} \mathrm{ND}=$ Data not available.

clinical trials should be carried out to directly relate thermal asymmetries with their causes.

It has been suggested that a $\Delta T_{\text {sk }}$ over $1{ }^{\circ} \mathrm{C}$ can be considered a strong indicator of abnormality (Ben-Eliyahu, 1992), requiring further diagnostic protocols to identify the cause of this difference.

Other authors are more rigorous and set values of $0.62{ }^{\circ} \mathrm{C}$ (Feldman and Nickoloff, 1984) or $0.5{ }^{\circ} \mathrm{C}$ (Niu et al., 2001; Uematsu's, 1985) as the reference points for abnormal contralateral $\Delta T_{\mathrm{sk}}$. In the present study, the highest mean $\Delta T_{\mathrm{sk}}$ values were $0.5{ }^{\circ} \mathrm{C}$ for women in the ventral hand and dorsal forearm and $0.3^{\circ} \mathrm{C}$ for men in the dorsal forearm.

Figs. 2 and 3 provide interesting information concerning the limit value of $0.5^{\circ} \mathrm{C}$ as a normal contralateral $\Delta T_{\text {sk }}$. It should be noted that the thigh and leg regions were those with the most thermal symmetry. The data from this study indicate a consistent symmetrical distribution of the human $T_{\text {sk }}$ (Figs. 2 and 3 ).
Kolosovas-Machuca and González, 2011 evaluated 42 measurement points and considered the maximum average $\Delta T_{\text {sk }}$ in children to be $0.7^{\circ} \mathrm{C}$. In our study, the highest average $\Delta T_{\text {sk }}$ recorded in adults was $0.3{ }^{\circ} \mathrm{C}$ (see Table 1 ); these values are clearly lower than those obtained by Zhu and Xin (1999) in China, who reported a maximum of $1.8^{\circ} \mathrm{C}$. Other studies indicate a maximum average $\Delta T_{\text {sk }}$ of $0.5^{\circ} \mathrm{C}$ (Niu et al., 2001), $0.67{ }^{\circ} \mathrm{C}$ in the toe region (Uematsu et al., 1988), or $0.64{ }^{\circ} \mathrm{C}$ in the heel region (Zaproudina et al., 2008). These reported differences make clear the need for large population studies, as certain characteristics of a race or physiological responses may affect the thermal behavior of each ROI and consequently the normal range of $T_{\text {sk }}$.

Some studies (Sivanandam et al., 2012; Ring et al.,2004; Huygen et al., 2004; Zhu and Xin, 1999; Ben-Eliyahu, 1992) have focused on comparing the thermal profile of healthy people to that of people with an established diagnosis. The $\Delta T_{\mathrm{sk}}$ in healthy 
people was found to usually be below $0.5^{\circ} \mathrm{C}$. However, in people with a diagnosed injury, contralateral $\Delta T_{\mathrm{sk}}$ tend to be higher, with $\Delta T_{\text {sk }}$ values up to $5.9{ }^{\circ} \mathrm{C}$ (Zhu and Xin, 1999).

The evaluation criteria for contralateral $\Delta T_{\mathrm{sk}}$ may also vary depending on the type of analysis that is attempted. Han et al. (2010) propose an upper threshold of $0.6{ }^{\circ} \mathrm{C}$ to indicate herpes zoster infection both in the face and trunk. Hildebrandt and Raschner (2010) identified an asymmetrical $T_{\text {sk }}$ as a predictor for pre-symptomatic identification of overuse injuries and considered IRT as an effective injury prevention method. This application was implemented in a Spanish professional football team with positive results over a preseason, with a $90 \%$ reduction in the number of days absent from training caused by injury among the players (Gómez-Carmona et al., 2011).

We did not record the subjects' hand and foot dominances, however, there is some evidence of increased $T_{\mathrm{sk}}$ in the dominant limb both in normal subjects (Smith et al., 1986) and in athletes (Gómez-Carmona et al., 2009; Arnaiz-Lastras et al., 2011). Determination of dominant side asymmetries could be important for better understanding the normal thermal profiles of athletes with high unilateral physical workload (i.e., tennis or fencing) but might be less relevant in other sports such as cycling.

Our data suggest that, for a healthy population of Brazilian adults, normal contralateral mean $\Delta T_{\mathrm{sk}}$ should be considered $0.3{ }^{\circ} \mathrm{C}$ or less, similar to that observed in the Chinese population (Zhu and Xin, 1999).

\subsection{Data}

Thermographic data are important to establish baselines, but factors such as specific population characteristics, evaluated ROI, the cameras used and their operation and environmental conditions can affect the results. These factors should be considered when comparing with data from different studies.

Our average values for the 24 monitored ROI approximate the data obtained by Niu et al. (2001) and Zaproudina et al. (2008) however, they are lower than the results presented by Zhu and Xin (1999), Cabrera et al. (2008) and Sivanandam et al. (2012). These differences in results may be based on a number of influencing factors such as the data collection time, room temperature (Ammer and Ring, 2008), type of camera used (Nguyen et al., 2010) and race of the subject (Zhu and Xin, 1999). For a better comparison of data in future studies, it is important to indicate the criteria and conditions for data collection and to identify the cameras used.

The results from Table 1 indicate a $\Delta T_{\text {sk }}$ of approximately 3$4{ }^{\circ} \mathrm{C}$ between the central and distal regions of the body. This condition is considered normal because the central regions have a higher $T_{\mathrm{sk}}$ than the extremities (Niu et al., 2001; Cabrera et al., 2008; Zhu and Xin, 1999). $T_{\text {sk }}$ differences are mainly caused by sympathetic neural activation in the acral regions, which is controlled by adrenergic vasoconstrictor nerve activity (Pascoe et al., 2008). Additionally, central regions have temperatures 5$6{ }^{\circ} \mathrm{C}$ higher than distal body parts because they contain organs such as the heart, liver and intestines, which generate a large amount of metabolic heat (Campbell, 2008).

The $T_{\mathrm{sk}}$ values differ depending on the study. Niu et al. (2001) observed that the highest $T_{\text {sk }}$ was on the neck $\left(31.9 \pm 0.6^{\circ} \mathrm{C}\right)$ and the lowest was on the toes $\left(27.5 \pm 2.0^{\circ} \mathrm{C}\right)$. Another example was presented by Cabrera et al. (2008) who found the highest $T_{\text {sk }}$ on the shoulders $\left(34.2 \pm 2.7^{\circ} \mathrm{C}\right)$ and the lowest on the dorsal feet $\left(29.8 \pm 3.4{ }^{\circ} \mathrm{C}\right)$, which represents a $\Delta T_{\text {sk }}$ of $4.32{ }^{\circ} \mathrm{C}$ between the maximum and minimum $T_{\mathrm{sk}}$ values of the body. There is strong evidence for considering the forehead, upper trunk and anterior neck as the regions with the highest $T_{\mathrm{sk}}$; the lowest $T_{\mathrm{sk}}$ are located on the toes and the soles of the feet (Cabrera et al., 2008).
After evaluating 84 ROI in 25 children, Kolosovas-Machuca (2011) also observed this trend by establishing $5.1^{\circ} \mathrm{C}$ as the maximum $T_{\mathrm{sk}}$ variation in the cranio-caudal axis and $0.7{ }^{\circ} \mathrm{C}$ in the transversal axis. Zhu and Xin (1999) assessed adult Chinese to find $\Delta T_{\text {sk }}$ up to $9.0^{\circ} \mathrm{C}$ on the y-axis and up to $1.8^{\circ} \mathrm{C}$ on the $\mathrm{x}$-axis. Vardasca (2010) proposed a normality condition considering the maximal thermal sagittal symmetry as $0.49 \pm 0.29{ }^{\circ} \mathrm{C}$. It seems clear that greater $\Delta T_{\mathrm{sk}}$ values can be expected in adults than in children.

There is marked individual variation in $T_{\mathrm{sk}}$ at rest. $\Delta T_{\mathrm{sk}}$ values have been observed in the palm of up to $9.1^{\circ} \mathrm{C}$ (Zaproudina et al., 2008), and in the fingers of up to $9.5^{\circ} \mathrm{C}$ (Niu et al., 2001). It therefore becomes necessary to establish a specific $T_{\text {sk }}$ reference for each body region. It would be a mistake to establish a unique range of normal $T_{\mathrm{sk}}$ for the whole body as has been established for core temperature.

Cabrera et al. (2008) proposes clear data for 28 ROI including muscle and joint regions, but they present only averages without providing any comment about gender and age factors. However, their work is interesting as a starting point for the interpretation of a thermal image.

Our study shows five percentile values for each ROI that can help to determine when an area is within the normal range or in a state of slight hypothermia $\left(<P_{10}\right)$, hypothermia $\left(<P_{5}\right)$, slight hyperthermia $\left(>P_{90}\right)$ or hyperthermia $\left(>P_{95}\right)$. Considering the variety of joints and muscle groups, it seems necessary to provide specific thermal profiles including these areas. Most works in the literature (Zaproudina et al., 2008; Uematsu et al.,1988; Zhu and Xin, 1999; Niu et al., 2001; Vardasca 2010; Kolosovas-Machuca and González, 2011) report only the mean and standard deviation data, which are important but are not sufficient for an accurate analysis of thermal data.

Our work considers only $24 \mathrm{ROI}$, although there are studies that subdivide the body into more ROI (Uemtsu et al., 1988, Niu et al., 2001; Zaproudina et al., 2008; Cabrera et al., 2008), with up to 84 ROI evaluated by Kolosovas-Machuca and González (2011). Regardless of the number of ROI, it becomes necessary to determine the expected thermal behavior for each region evaluated. Knowing the expected thermal behavior is important for practical analysis, as in the case of a physician who is evaluating a patient with a shoulder bursitis, a physical therapist who is involved in the reco of a knee after a long period of immobilization, or a coach who is evaluating the reco of an athlete by $T_{\text {sk }}$ after performing an exercise. data such as that presented in this study may be a useful tool for establishing the normal $T_{\mathrm{sk}}$ ranges or to encourage the investigator to find the factor that is causing the abnormality (in the examples above, inflammation of the shoulder, poor neural activation or muscle activity, or an overload in a concrete muscle group of the athlete, respectively) considering the data for the specific population group (bursitis patients, knee convalescent, or athletes) or, even better, the previous records of the same subject.

\subsection{Male vs female}

Our results (Table 1 ) aim to consider gender as a determining factor for $T_{\mathrm{sk}}$ because $59 \%$ of the 22 considered ROI showed significant differences by gender at a $p<0.05$ level. Regions without significant differences were the ventral and dorsal hand, ventral leg, abdomen and lower back. These data suggest that for only the indicated ROI, a unique $T_{\mathrm{sk}}$ reference would be valid for both men and women.

Results from Niu et al. (2001) were similar to our data, showing non-significant differences in the dorsal hand and abdomen by gender. Moreover, the anterior and posterior hypochondrium and the feet were indicated by Zhu and Xin (1999) as the regions with the highest $\Delta T_{\mathrm{sk}}$ between men and women. 
Table A1

$T_{\text {sk }}\left({ }^{\circ} \mathrm{C}\right)$ percentiles $\left(P_{5}, P_{10}, P_{50}, P_{90}\right.$ and $\left.P_{95}\right)$ for female and male Brazilian adults.

\begin{tabular}{|c|c|c|c|c|c|c|c|c|c|c|}
\hline \multirow[t]{2}{*}{ ROI } & \multicolumn{5}{|l|}{ Male } & \multicolumn{5}{|c|}{ Female } \\
\hline & $P_{5}$ & $P_{10}$ & $P_{50}$ & $P_{90}$ & $P_{95}$ & $P_{5}$ & $P_{10}$ & $P_{50}$ & $P_{90}$ & $P_{95}$ \\
\hline \multicolumn{11}{|l|}{ Ventral hand } \\
\hline $\mathrm{R}$ & 24.02 & 24.84 & 27.80 & 31.70 & 33.04 & 24.38 & 25.14 & 28.60 & 31.02 & 31.60 \\
\hline $\mathrm{L}$ & 24.54 & 25.04 & 28.00 & 32.12 & 33.06 & 24.79 & 25.20 & 28.70 & 31.32 & 32.01 \\
\hline \multicolumn{11}{|c|}{ Ventral forearm } \\
\hline $\mathrm{R}$ & 28.80 & 29.40 & 30.60 & 32.16 & 32.60 & 28.28 & 28.78 & 30.40 & 32.02 & 32.20 \\
\hline $\mathrm{L}$ & 28.82 & 29.34 & 31.00 & 32.32 & 32.78 & 28.69 & 29.10 & 30.50 & 32.40 & 32.60 \\
\hline \multicolumn{11}{|l|}{ Ventral arm } \\
\hline $\mathrm{R}$ & 29.14 & 29.50 & 31.30 & 32.76 & 33.08 & 28.50 & 29.00 & 30.80 & 32.40 & 32.80 \\
\hline $\mathrm{L}$ & 29.04 & 29.60 & 31.40 & 33.06 & 33.40 & 28.78 & 29.28 & 31.20 & 32.82 & 33.02 \\
\hline \multicolumn{11}{|c|}{ Ventral thigh } \\
\hline $\mathrm{R}$ & 27.62 & 28.08 & 29.80 & 31.10 & 31.40 & 26.20 & 26.58 & 28.70 & 30.10 & 30.53 \\
\hline $\mathrm{L}$ & 27.52 & 28.10 & 29.80 & 31.30 & 31.58 & 26.30 & 26.98 & 28.80 & 30.22 & 30.51 \\
\hline \multicolumn{11}{|l|}{ Ventral leg } \\
\hline $\mathrm{R}$ & 27.82 & 28.34 & 30.30 & 31.80 & 32.20 & 27.59 & 28.48 & 30.20 & 31.72 & 31.91 \\
\hline $\mathrm{L}$ & 27.80 & 28.24 & 30.30 & 31.96 & 32.28 & 27.89 & 28.38 & 30.30 & 31.64 & 32.10 \\
\hline Chest & 30.02 & 30.06 & 31.90 & 32.86 & 33.26 & - & - & - & - & - \\
\hline Abdomen & 29.80 & 30.08 & 31.50 & 33.06 & 33.40 & 28.99 & 29.50 & 31.30 & 33.32 & 33.62 \\
\hline \multicolumn{11}{|l|}{ Dorsal hand } \\
\hline $\mathrm{R}$ & 25.02 & 25.40 & 27.90 & 30.96 & 32.24 & 25.30 & 25.86 & 28.60 & 31.22 & 31.70 \\
\hline $\mathrm{L}$ & 24.40 & 25.30 & 27.70 & 30.70 & 31.54 & 25.40 & 25.68 & 28.10 & 30.90 & 31.51 \\
\hline \multicolumn{11}{|c|}{ Dorsal forearm } \\
\hline $\mathrm{R}$ & 28.96 & 29.50 & 30.70 & 31.86 & 32.30 & 27.89 & 28.40 & 30.30 & 31.62 & 32.10 \\
\hline $\mathrm{L}$ & 28.62 & 28.94 & 30.40 & 31.60 & 31.86 & 27.69 & 28.48 & 30.10 & 31.40 & 31.70 \\
\hline \multicolumn{11}{|l|}{ Dorsal arm } \\
\hline $\mathrm{R}$ & 27.30 & 27.78 & 29.40 & 30.86 & 31.52 & 25.67 & 26.88 & 28.60 & 30.32 & 30.66 \\
\hline $\mathrm{L}$ & 26.94 & 27.64 & 29.30 & 30.56 & 30.90 & 25.58 & 26.90 & 28.50 & 30.24 & 30.72 \\
\hline \multicolumn{11}{|c|}{ Posterior Thigh } \\
\hline $\mathrm{R}$ & 28.30 & 28.80 & 30.40 & 31.70 & 32.10 & 27.09 & 27.68 & 29.40 & 30.70 & 31.01 \\
\hline $\mathrm{L}$ & 28.04 & 28.64 & 30.30 & 31.76 & 32.08 & 27.00 & 27.28 & 29.40 & 30.52 & 30.82 \\
\hline \multicolumn{11}{|l|}{ Calf } \\
\hline $\mathrm{R}$ & 27.42 & 28.10 & 30.20 & 31.56 & 31.90 & 27.20 & 27.88 & 29.20 & 30.60 & 30.70 \\
\hline $\mathrm{L}$ & 27.62 & 27.90 & 30.10 & 31.52 & 31.80 & 26.88 & 27.60 & 29.00 & 30.40 & 30.60 \\
\hline Upper back & 30.44 & 31.10 & 32.30 & 33.10 & 33.38 & - & - & - & - & - \\
\hline Low back & 29.84 & 30.14 & 31.60 & 32.76 & 33.28 & 29.49 & 29.80 & 31.10 & 33.10 & 33.54 \\
\hline
\end{tabular}

Note: $\mathrm{R}=$ Right; $\mathrm{L}=$ Left

Kolosovas-Machuca and González (2011) also compared $T_{\text {sk }}$ by gender, but in children. The largest $\Delta T_{\mathrm{sk}}$ obtained was $0.8^{\circ} \mathrm{C}$ in the cheek and neck, but in $58.3 \%$ of the 84 evaluated ROI, the $\Delta T_{\text {sk }}$ were equal to or lower than $0.5{ }^{\circ} \mathrm{C}$; Therefore, the authors concluded that $T_{\mathrm{sk}}$ in children were independent of gender. These results also agree with Agarwal (2010), who did not see an influence from gender after evaluating the $T_{\mathrm{sk}}$ of 50 healthy subjects (29 females and 21 male; aged 32.8 years).

However, data from our study indicate that in most of the evaluated ROI, absolute differences were less than $0.5^{\circ} \mathrm{C}$ (Table 1 ). In the thigh region (dorsal and ventral), the $\Delta T_{\mathrm{sk}}$ were elevated $\left(\Delta T_{\mathrm{sk}} \approx 1.0^{\circ} \mathrm{C}\right)$, followed by the calf $\left(\Delta T_{\mathrm{sk}} \approx 0.8^{\circ} \mathrm{C}\right)$ and the dorsal arm $\left(\Delta T_{\mathrm{sk}} \approx 0.7^{\circ} \mathrm{C}\right)$. Despite the lack of data about body composition, the $\Delta T_{\text {sk }}$ on these areas may be caused by a greater accumulation of body fat in women or higher muscle mass development in men. Thus, it is inappropriate to use the same $T_{\text {sk }}$ reference values in these regions. We recommend the design of specific $T_{\mathrm{sk}}$ tables for these regions that consider gender.

Further research about the influence of gender on the recorded $T_{\mathrm{sk}}$ is required to fully understand the skin thermal response and to set specific values for both men and women.

\section{Conclusion}

Different $T_{\text {sk }}$ for each ROI and many incident factors provide particular thermal profiles, making specific reference tables necessary to establish the normal conditions for each population group.
There is a marked state of thermal equilibrium for contralateral ROI. We suggest the value of $0.5^{\circ} \mathrm{C}$ as a normal limit for contralateral $\Delta T_{\mathrm{sk}}$. Gender seems to be a determining factor for the $T_{\mathrm{sk}}$ of the thigh, calf and dorsal arm, making it necessary to apply specific tables for analyzing the $T_{\mathrm{sk}}$ of these regions by gender. However, the hands, ventral leg, abdomen and lower back reference values are similar in both sexes.

\section{Acknowledgments}

This study was supported by Conselho Nacional de Pesquisa (CNPq) - Brazil: Post-Doctoral Fellowship.

\section{Appendix A}

See appendix Table A1

\section{References}

Acharya, U.R., Ng, E.Y., Tan, J.H., Sree, S.V., 2012. Thermography based breast cancer detection using texture features and support vector machine. J. Med. Syst. 36, 1503-1510.

Agarwal, K., 2010. Thermographic imaging in healthy humans - what is normal skin temperature? Thermol. Int. 20, 140.

Akimov, E.B., Andreev, R.S, Kalenov, IuN., Kirdin, A.A., Son'kin, V.D., Tonevitskiı̌, A.G., 2010. Human temperature portrait and its relations with aerobic working capacity and the level of blood lactate. Fiziol. Cheloveka. 36, 89-101. 
Al-Nakhli, H.H., Petrofsky, J.S., Laymon, M.S., Berk, L.S., 2012. The use of thermal infra-red imaging to detect delayed onset muscle soreness. J. Vis. Exp. 22, 3551 (pII).

Ammer, K., Ring, F.R., 2008. Standard procedures for infrared imaging in medicine. In: Diakides, N.A., Bronzin, J.D. (Eds.), Medical Infrared Imaging. Cr Press, Boca Raton, pp. 22-1-22-14

Ammer, K., 2010. Thermography in spinal disorders-a narrative review. Thermol. Int. 20, 117-125.

Arnaiz-Lastras, J., Fernández-Cuevas, I., Gómez-Carmona, P.M., Sillero-Quintana, M., García, M.A., Piñonosa, C.S., 2011. Pilot study to determinate thermal asymmetries in judokas. In: Proceedings of the 16th Annual Congress of the European College of Sport Sciences ECSS. Liverpool, United Kingdom, p. 107.

Arora, N., Martins, D., Ruggerio, D., Tousimis, E., Swistel, A.J., Osborne, M.P., Simmons, R.M., 2008. Effectiveness of a noninvasive digital infrared thermal imaging system in the detection of breast cancer. Am. J. Surg. 196, 523-526.

Ben-Eliyahu, D.J., 1992. Infrared thermographic imaging in the detection of sympathetic dysfunction in patients with patellofemoral pain. J. Manip. Physiol. Ther. 15, 164-170.

Brisoschi, M.C., Macedo, J.F., Macedo, R.A., 2003. Termometria cutânea: novos conceitos. J. Vas. Bras. 2, 151-160.

Cabrera, I.N., Cohen, J.M., Downing, L.D., 2008. Thermography Techniques. In: Lee, M.H.M., Cohen, J.M. (Eds.), Rehabilitation Medicine and Thermography. Impress Publications, Wilsonville, pp. 25.-32

Campbell, I., 2008. Body temperature and its regulation. Anaesth. Intensive Care Med. 9, 259-263.

Charkoudian, N., 2010. Mechanisms and modifiers of reflex induced cutaneous vasodilation and vasoconstriction in humans. J. Appl. Physiol. 109, 1221-1228.

Cheuvront, S.N., Kenefick, R.W., Montain, S.J., Sawka, M.N., 2010. Mechanisms of aerobic performance impairment with heat stress and dehydration. J. Appl. Physiol. 109, 1989-1995.

Falk, B., Dotan, R., 2011. Temperature regulation and elite young athletes. Med. Sport. Sci. 56, 126-149.

Feldman, F., Nickoloff, E.L., 1984. Normal thermographic standards for the cervical spine and upper extremities. Skelet. Radiol. 12, 235-249.

Garagiola, U., Giani, E., 1990. Use of telethermography in the management of sports injuries. Sports Med. 10, 267-272.

George, J., Bensafi, A., Schmitt, A.M., Black, D., Dahan, S., Loche, F., Lagarde, J.M., 2008. Validation of a non-contact technique for local skin temperature measurements. Skin Res. Technol. 14, 381-384.

Gómez-Carmona, P.M., Noya-Salces, J., Núñez, J., Fernández-Rodríguez, I., SilleroQuintana, M., 2009. Validation of infrared thermography as injury prevention method in professional soccer players. In: Proceedings of the 14th Annual Congress of the European College of Sport Sciences ECSS. Oslo, Norway, p. 116.

Gómez-Carmona, P.S., Sillero-Quintana, M., Fernandez-Cuevas, I., Noya, S.J., Fernández, R.I., 2011. Application of an injury prevention protocol based on infrared thermography in professional soccer players during pre-season. Thermol. Int. $21,124$.

Gonzales, B.R., Hagin, V., Guillot, R., Placet, V., Groslambert, A., 2011. Effects of polyester jerseys on psycho-physiological responses during exercise in a hot and moist environment. J. Strength Cond. Res. 25, 3432-3438.

Han, S.S., Jung, C.H, Lee, S.C., Jung, H.J., Kim, Y.H., 2010. Does skin temperature difference as measured by infrared thermography within 6 months of acute herpes zoster infection correlate with pain level? Skin Res. Technol. 16, $198-201$.

Herry, C.L., Frize, M., 2004. Quantitative assessment of pain-related thermal dysfunction through clinical digital infrared thermal imaging. BioMed. Eng. Online 3, 19.

Hildebrandt, C., Raschner, C., 2010. Recording sports injuries with thermography. Thermol. Int. 20, 145.

Hildebrandt, C., Raschner, C., Ammer, K., 2010. An overview of recent application of medical infrared thermography in sports medicine in Austria. Sensors 10 , 4700-4715.

Howell, K.J., Lavorato, A., Visentin, M.T., Smith, R.E., Schaefer, G., Jones, C.D., Weibel, L., Denton, C.P., Harper, J.I., Woo, P., 2009. Validation of a protocol for the assessment of skin temperature and blood flow in childhood localised scleroderma. Skin Res. Technol. 15, 346-356.

Huang, C.L., Wu, Y.W., Hwang, C.L., Jong, Y.S., Chao, C.L., Chen, W.J., Wu, Y.T., Yang, W.S., 2011. The application of infrared thermography in evaluation of patients at high risk for lower extremity peripheral arterial disease. J. Vasc. Surg. 54, 1074-1080.

Huygen, F.J., Niehof, S., Klein, J., Zijlstra, F.J., 2004. Computer-assisted skin videothermography is a highly sensitive quality tool in the diagnosis and monitoring of complex regional pain syndrome type I. Eur. J. Appl. Physiol. 91, $516-524$.

Jiang, L.J., Ng, E.Y., Yeo, A.C., Wu, S., Pan, F., Yau, W.Y., Chen, JH., Yang, Y.A., 2005. perspective on medical infrared imaging. J. Med. Eng. Technol. 29, 257-267.
Johnson, J.M., Kellogg Jr, D.L., 2010. Local thermal control of the human cutaneous circulation. J. Appl. Physiol. 109, 1229-1238.

Kolosovas-Machuca, E.S., González, F.J., 2011. Distribution of skin temperature in Mexican children. Skin Res. Technol. 22, 1-6.

Magalhães, F.C., Passos, R.L., Fonseca, M.A., Oliveira, K.P., Ferreira-Júnior, J.B., Martini, A.R., Lima, M.R., Guimarães, J.B, Baraúna, V.G, Silami-Garcia, E., Rodrigues, L.O., 2010. Thermoregulatory efficiency is increased after heat acclimation in tropical natives. J. Physiol. Anthropol. 29, 1-12.

Marins, J.B., Fernández-Cuevas, I., Ribot-Serrano, J., Garcia-Comcepción, M.A. Gómez-Carmona, P., Sillero-Quintana, M., 2012a. Thermal response of skin temperature on muscle and joint body areas after strength training by infrared thermography. Thermol. Int. 22, 119.

Marins, J.B., Fernadez-Cuevas, I., Ribot-Serrano, J., Garcia-Concepción, M.A., GómezCarmona, P., Sillero-Quintana, M., 2012b. Respuesta de la temperatura en la piel durante periodo de recuperación de un ejercicio aerobio. Arch. Med. Deporte. $29,874-875$.

Merla, A., Iodice, P., Tangherlini, A., De Michele, G., Di Romualdo, S., Saggini, R. Romani, G., 2005. Monitoring skin temperature in trained and untrained subjects throughout thermal video. Conf. Proc. IEEE Eng. Med. Biol. Soc. 2, 1684-1686.

Merla, A., Mattei, P.A., Di Donato, L., Romani, G.L., 2010. Thermal imaging of cutaneous temperature modifications in runners during graded exercise. Ann. Biomed. Eng. 38, 158-163.

Merla, A., Romani, G.L., 2008. Biomedical applications of functional infrared imaging. In: Diakides, N.A., Bronzin, J.D. (Eds.), Medical Infrared Imaging. $\mathrm{Cr}$ Press, Boca Raton, pp. 15-1-15-20

Morris, J.G., Nevill, M.E., Boobis, L.H., Macdonald, I.A., Williams, C., 2005. Muscle metabolism, temperature, and function during prolonged, intermittent, highintensity running in air temperatures of 33 degrees and 17 degrees C. Int. J. Sports Med. 26, 805-814.

Nguyen, A.V., Cohen, N.J., Lipman, H., Brown, C.M., Molinari, N.A., Jackson, W.L., Kirking, H., Szymanowski, P., Wilson, T.W., Salhi, B.A, Roberts, R.R., Stryker, D W., Fishbein, D.B., 2010. Comparison of 3 infrared thermal detection systems and self-report for mass fever screening. Emerg. Infect. Dis. 16, 1710-1717.

Niu, H.H., Lui, P.W., Hu, J.S., Ting, C.K., Yin, Y.C., Lo, Y.L., Liu, L., Lee, T.Y., 2001 Thermal symmetry of skin temperature: data of normal subjects in Taiwan. Zhonghua Yi Xue Za Zhi (Taipei) 64, 459-468.

Park, J., Jang, W.S., Park, K.Y., Li, K., Seo, S.J., Hong, C.K., Lee, J.B., 2012. Thermography as a predictor of postherpetic neuralgia in acute herpes zoster patients: a preliminary study. Skin Res. Technol. 18, 88-93.

Pascoe, D., Mercer, J., Weerd, L., 2008. Physiology of thermal signals. In: Diakides, N.A. Bronzin, J.D. (Eds.), Medical Infrared imaging. Cr Press, Boca Raton, pp. 6-1-6-20

Ring, E., Ammer, K., Jung, A., Murawski, P., Wiecek, B., Zuber, J., Zwolenik, S. Plassmann, P., Jones, C., Jones, B.F., 2004. Standardization of infrared imaging. Conf. Proc. IEEE Eng. Med. Biol. Soc. 2, 1183-1185.

Ring, E.F., Ammer, K., 2012. Infrared thermal imaging in medicine. Physiol. Meas. 33 R33-R46.

Sillero-Quantana, M., Ferández-Cuevas, I., Gómez-Carmona, P., García, C.M.A., 2011 Application of thermography an injury prevention method in sports. Thermol Int. 21, 123.

Sivanandam, S., Anburajan, M., Venkatraman, B., Menaka, M., Sharath, D., 2012 Medical thermography: a diagnostic approach for type 2 diabetes based on non-contact infrared thermal imaging. Endocrine 42, 343-351.

Smith, B., Blander, M.K., Goodman, P.H., 1986. Dominant forearm hyperthermia: a study of fifteen athletes. Thermology 2, 25-28.

Uematsu, S., Edwin, D.H, Jankel, W.R., Kozikowski, J., Trattner, M., 1988. Quantification of thermal asymmetry. Part 1: Normal values and reproducibility. J Neurosurg. 69, 552-555.

Uematsu, S., 1985. Thermographic imaging of cutaneous sensory segment in patients with peripheral nerve injury. Skin-temperature stability between sides of the body. J. Neurosurg. 62, 716-720.

Vardasca, R., 2011. Thermal symmetry of the limbs in healthy subjects. Thermol. Int. $21,146$.

Werner, J., 2010. System properties, feedback control and effector coordination of human temperature regulation. Eur. J. Appl. Physiol. 109, 13-25.

Zaproudina, N., Ming, Z., Hänninen, O.O., 2006. Plantar infrared thermography measurements and low back pain intensity. J. Manipulative Physiol. Ther. 29 219-223.

Zaproudina, N., Varmavuo, V., Airaksinen, O., Närhi, M., 2008. Reproducibility of infrared thermography measurements in healthy individuals. Physiol. Meas. 29 515-524.

Zhu, W.P., Xin, X.R., 1999. Study on the distribution pattern of skin temperature in normal Chinese and detection of the depth of early burn wound by infrared thermography. Ann. NY. Acad. Sci. 888, 300-313. 